Military Technical College

Kobry El-Kobbah,

Cairo, Egypt

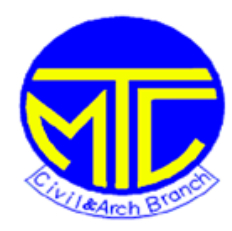

$11^{\text {th }}$ International Conference on Civil and Architecture Engineering

ICCAE-11-2016

\title{
3D Modeling and Analysis of Jointed Rigid Airfield Pavement using ABAQUS
}

\author{
SaadA. El-Hamrawy ${ }^{1}$, Ahmed E.Abu El-Maaty ${ }^{2}$,Ghada M.Hekal ${ }^{3}$ and Eman M. Salah El-Din ${ }^{4}$ \\ 1.Prof .of Highways and Airports Engineering,Menoufia University,Egypt. \\ 2.Associate Professorof Highways and Airports Engineering,Menoufia University, Egypt. \\ 3.Lecturer ofStructural Engineering, Menoufia University, Egypt. \\ 4. B.Sc., Civil Engineering Department,Menoufia University, Egypt.
}

\begin{abstract}
:
Rigid pavements are complex structural systems that are composed of numerous discrete concrete slabs, longitudinal and transverse joints are provided between the slabs, which may or may not include dowel bars. Dowel bars connect concrete slabs and transfer wheel load across the joint primarily through shear force.

Many response models based on the finite element method have been developed for the analysis of jointed pavement slabs. Despite the notable improvement, important considerations were overlooked. Such approximation may affect the results obtained at the joint and cause it to be unrealistic. In the current research,the development of finite element modelwas conducted using the finite element code ABAQUS(6.13). The required modeling techniques for developing this model are illustrated , this include the meshing techniques, boundary condition, analysis process and required techniques for each case was included. Verification process was presented to ensure model reliability. The final step involves solving themodel, calculating the stresses, and analysis of the results.
\end{abstract}

Keywords: ABAQUS Finite element software, Rigid pavement, Airfield,Jointed concrete slabs, load transfer efficiency

\section{INTRODUCTION}

In 1926, Westergaard developed a response model for rigid pavement of a slabs-on-grade subjected to wheel loads by modeling the pavement as a thin, infinite or semi-infinite plate resting on a bed of springs [1]. It was suggested that a $25 \%$ of the load transfers to the adjacent slab was an appropriate design value for load transfer [2]. The federal aviation administration developed a new design procedure program called (FAARFIELD). However, it continues to consider the $25 \%$ of the load transfers to the adjacent slab through the joint.

The finite element method has become a widely used tool for rigid pavement analysis since the early 1970s. Despite notable improvement, some important aspects of the JPCCP problems have been neglected. The 3D-FE models developed for rigid pavements either have neglected modeling dowel bars or modeled their effect byusing beam or spring elements and therefore the dowel/concrete interface is not represented. Such approximation may affect the results obtained at the joint and cause it to be unrealistic. The foundation representation usually as Winkler foundation, the effect interaction with the slab or base was not accounted for. In addition, simulation of the lift-off of the pavements, especially when curling or warping due to temperature gradients occurs was not accounted for. Moving-axle load is applied on the slab as a static load or as a short duration pulse applied at a specific position on the slab. Although these methods represented pavement response due to dynamic loads, they could not capture some significant details in analyzing the modes of 
failure of concrete pavements such as the effect of dowel bar vibration on the stiffness of the surrounding concrete. Most of the previous studies used low grade meshing element, using poor grade element without a convenient type of formulation and integration affect the accuracy of the obtained results and the time which the model take until it converges. Load transfer across the transverse joints through aggregate interlock has been modeled by shear spring elements; this approximation does not simulate the true behavior of aggregate interlock.

A 3D, nonlinear, dynamic, finite element model was developed to study the pavement response with doweled joints. ABAQUS is a general-purpose, commercial, nonlinear finite element code, which is used in this study. This software provides numerous interactions, constraints, mesh generators, and different loading conditions, which make it suitable to carry out a complicated dynamic analysis. The model is developed to overcome the shortcomings of previous studies in terms of handling the different types of loading conditions affecting the pavement such dynamic loading and their characteristics. The model also handles interfaces with gaps, friction and the sliding characteristics between dowel bars and the surrounding concrete pavements.

\section{Model description}

The pavement system upon which the models are based was selected based on a typical rigid pavement designed for use in Egypt. The 3D finite element model developed in this study consists of two dowel jointed concrete slabssupported by base, subbase and subgrade as shown in Figure (1).To avoid problems associated with boundary conditions, the concrete slabs were modeled attheir full widths of $5.0 \mathrm{~m}$ with full lengths of $5.0 \mathrm{~m}$. The base, subbase and subgrade aremodeled slightly wider than the slab to enable a better distribution of the stresses and widened by $0.5 \mathrm{~m}$ on each sideof the slab. The two adjacent slabs are connected with 14 dowel bars placed at $350 \mathrm{~mm}$ spacing center to center, at mid-height of the slab. The dowel bars are $32 \mathrm{~mm}$ in diameter and $500 \mathrm{~mm}$ in length, the slab thickness is $340 \mathrm{~mm}$. The slabs lie on top of a $150 \mathrm{~mm}$-thick of base layer. The extension of the subbase layer is $250 \mathrm{~mm}$. The extension of the subgrade layer is $2.5 \mathrm{~m}$ to ensure better simulation of subgrade responses as approximation of the infinite foundation. The main model has Zero gap between the two adjacent slabs to take combined effect of aggregateinterlock and dowel bar as load transfer efficiencies devices.

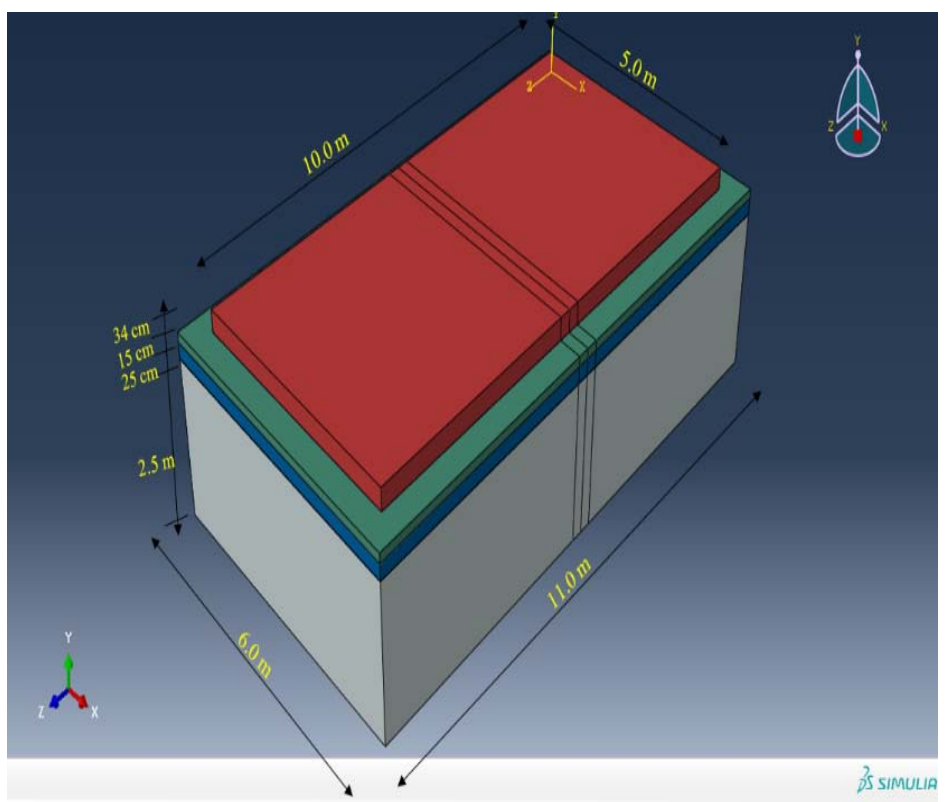

Figure (1): Three-dimensional model assembly and the detailed The X-Y view of the assembly 


\section{Pavement material models}

In ABAQUS, Various constitutive models have been developed to describe the nonlinearity behavior of concrete such the smeared crack concrete model, the brittle cracking model, and the concrete damaged plasticity model. In this study, concrete damaged plasticity model is used as it isdesigned for applications in which the concrete is subjected to arbitrary loading conditions, like cyclic, and/or dynamic loading under low confining pressures. The concrete damaged plasticity model can be used in combination with material damping[3].

The main parametersrequired for defining the plastic damage model were Dilation angle,Eccentricity, $\mathrm{F}_{\mathrm{b}} / \mathrm{f}_{\mathrm{c}}, \mathrm{K}$, Viscosity parameter.These parameters are assumed $38^{\circ}, 0.1,1.16,2 / 3$ andzero respectively. Also concrete compression hardening and damage was defined as well concrete tension damage and stiffening.[4]

Federal Aviation Administration, FAA, operates a state-of-the-art; full-scale pavement test facility dedicated solely to airport pavement at researchNational Airport Pavement Test Facility (NAPTF). A construction cycle 6 includes test pavement and instrumentation layout and materials testing data.Test items are designated using the 3-letter code MRS (referring to: medium-strength subgrade, rigid pavement structure, stabilized base), followed by a number and a letter. The number (1, 2, and 3 ) corresponds to the target strength of the concrete surface (500, 750 and 1000 psi respectively) [5].In the current study, CC6 data is used as concrete model input for the elastic behavior. The density is used to apply the self-weight loading on the concrete.

FAARFIELD program includes three items usually used in designing rigid pavement thickness, Item P-306- Econocrete Subbase Course, Item P-304 - Cement-Treated Base Course and Item P-301 Soil-Cement Base Course. The base materials were represented using elastic isotropic material models.

Solid elements were used to model the subbase and subgrade layers. The support soil was modeled as a homogeneous, isotropicelastic material. Data obtained from FAA report on developing FEDFAA program for rigid pavement model evaluation [6].

Modeling the dowel bars using solid brick elements accurately simulates the interaction between dowel bars and concrete. Dowel bars materials were represented using elastic isotropic material models[7]. The materialproperties constants used are listed in Table (1).

Table (1): Concrete, base, steel properties used for the finite element model

\begin{tabular}{|l|l|l|}
\hline Cases & Parameter & Value \\
\hline $\begin{array}{l}\text { PCC } \\
\text { slab } \\
\text { (MRS-1) }\end{array}$ & Modulus of elasticity & $3,800,000 \mathrm{psi}$ \\
\cline { 2 - 3 } & Poisson's ratio & 0.15 \\
\cline { 2 - 3 } & Density & $2400 \mathrm{~kg} / \mathrm{m}^{3}$ \\
\hline (MRS-2) & Modulus of elasticity & $5,700,000 \mathrm{psi}$ \\
\hline (MRS-3) & Modulus of elasticity & $7,600,000 \mathrm{psi}$ \\
\hline $\begin{array}{l}\text { Item P- } \\
\text { 306 }\end{array}$ & Modulus of elasticity & $700,000 \mathrm{psi}$ \\
\cline { 2 - 3 } & Poisson's ratio & 0.2 \\
\hline
\end{tabular}

\begin{tabular}{|l|l|l|}
\hline P-304 & Modulus of elasticity & $500,000 \mathrm{psi}$ \\
\hline P-301 & Modulus of elasticity & $250,000 \mathrm{psi}$ \\
\hline \multirow{4}{*}{ steel bar } & Modulus of elasticity & $210,000 \mathrm{MPa}$ \\
\cline { 2 - 3 } & Poisson's ratio & 0.3 \\
\hline $\begin{array}{l}\text { p-209 } \\
\text { subbase }\end{array}$ & Modulus of elasticity & 14,474 \\
\cline { 2 - 3 } & Poisson's ratio & 0.35 \\
\hline $\begin{array}{l}\text { Very low- } \\
\text { subgrade }\end{array}$ & Modulus of elasticity & 4,500 \\
\cline { 2 - 3 } & Poisson's ratio & 0.4 \\
\hline
\end{tabular}




\section{Modeling of interfaces}

Modeling the dowel bars using solid brick elements accurately simulates the interaction between dowel bars and concrete. The interface between half of the dowel bar in a slab and concrete has been modeled as a perfect bond and other half in the adjacent slab modeled such that the dowel bar can move in the slab along the dowel bar's axial direction. The tangential behavior of the dowel is modeled using coulomb frictional contact between the surfaces. Using the coulomb friction model at the contact surface allows for shear stress and slip at the interface to be modeled. To activate the coulomb friction model, gravity load has to beapplied to generate the appropriate contact forces.The different friction coefficients were taken as 0.05 for the perfectly bonded side and 0.3 for the free side of the dowel. Separation is allowed between the surfaces[8]. The normal behavior of the load transfer device is modeled by using hard contact pressure definition between the two surfaces. For this purpose, special surface-to-surface elements were used to model hard contact behavior, contact pressure-over closure relationship used by ABAQUS is referred to as the "hard" contact model.

The tangential behavior of surface between the slab and base was modeled as Isotropic coulomb friction. No shear stress limit is included. The 1993 AASHTO pavement design guide specifies a range for the coefficient of friction at the slab/base interface that falls between 0.9 and 2.2 depending on the base course type. The coefficient of friction between the concrete slab and the underlying base layer was assumed 1.5. Loss of contact between slab and foundation is modeled using hard normal contact that allows the surfaces to separate after coming in contact[9].

Since these two granular layers, no separation is allowed between foundation layers. The interaction between the top of the subbase and the bottom of base and the interaction between the bottom of the subbase and the top of subgrade was simulated by the use of appropriate hard contact interface elements and isotropic coulomb friction model, the coefficient of friction was assumed 1.5[9].

For the analysis of combined effect of aggregate interlock and dowel bars on load transfer, the side interface between the two adjacent slabs (along the transverse joint) is assumed to have zero spacing and a friction coefficient of 1.5 simulating limited aggregate interlocking[9].

\section{Meshing of the model}

Meshing irregularities in the model in non-uniform way can create stresses does not exist in real modes, so it is very important to insure uniform meshing around dowel bars to allow the model to capture accurately the dowel responses. To insure the regular distribution of mesh element around dowel bar, wedge elements with very fine meshing.The fine mesh enables accurate assessment of the contact stresses that develop around the dowelsare used to model the dowel bars.

Second-order elements clearly outperform first-order elements in problems with stress concentrations. However, contact problems, with convergence difficulties may arise with these elements. So first order 6-node linear triangular prism elements are used to model the dowel bars[3]. Reduced-integration elements tend to be somewhat more efficient-results are often as good as or better than full integration at lower computational cost. First-order, reduced-integration elements in ABAQUS include hourglass control, but they should be used with reasonably fine meshes. Hourglassing can also be minimized by distributing point loads and boundary conditions over a number of adjacent nodes.So, eight-node linear continuum three-dimensional brick element (C3D8R) with reduced order numerical integration with hourglass control available in ABAQUS (6.13) are used for discretizing the concrete slabs.

Realizing the fact that transverse joints, the region surrounding the dowel bars and loading path are critical stress zones that can initiate pavement failure, a refined mesh was developed at these region, to capture accurately the flow of stresses around the dowel bars. 


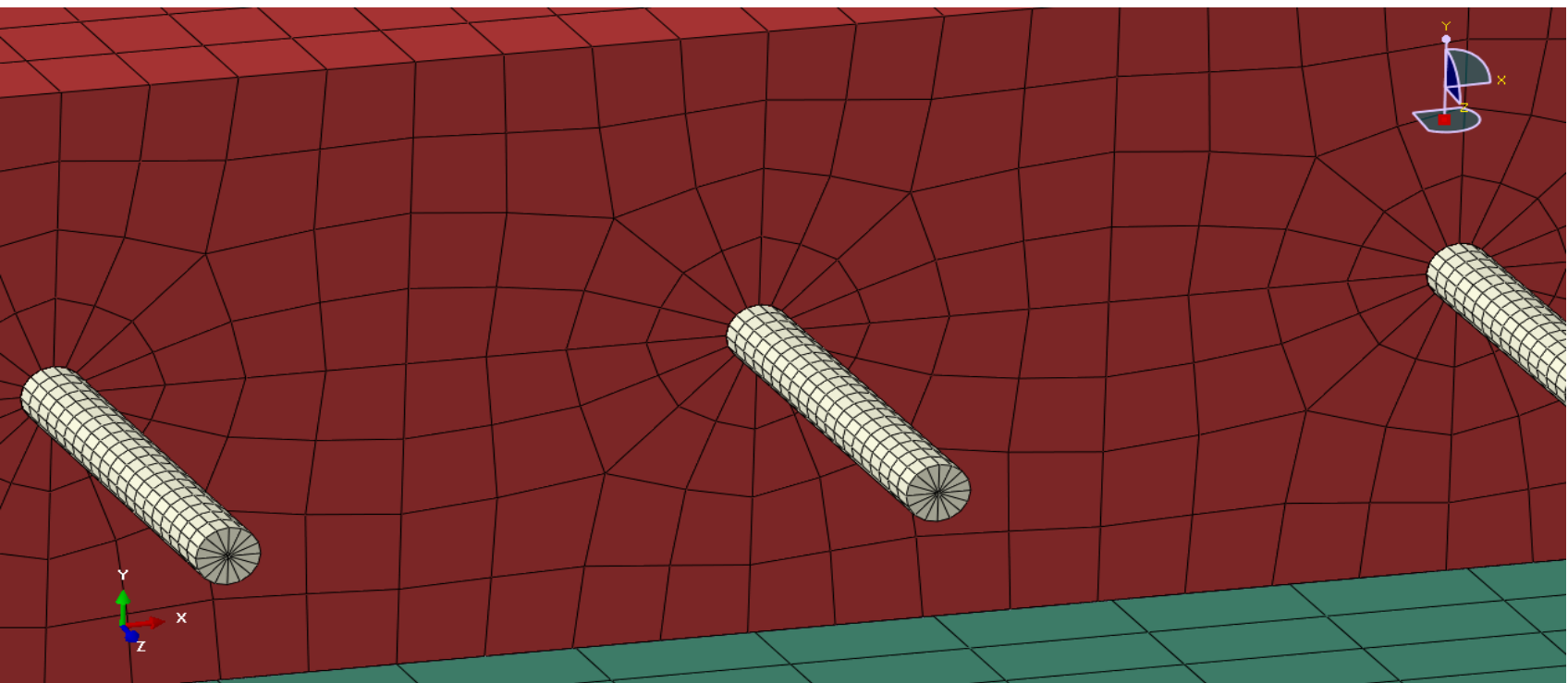

This element has the capability of representing large deformation, geometric and material nonlinear solid element (C3D8R) has three degrees of freedom at each node. All layers under the pavement (base, subbase and subgrade) are simulated with the same shape to preserve the continuity of nodes between consecutive layers. Figure (2) shows a cross section of the transverse joint modeled and meshing details.

Figure (2): Meshing details across the doweled pavement joint

\section{Boundary conditions}

The bedrock was assumed deep enough to simulate non-reflective boundaries, which simulate the semi-infinite extension of layers. All translational degrees offreedom were restrained at the bottom of the subgrade layer. The sides of subgrade boundaries were constrained in their Y-direction, and were applied at the sides of the base as well as all sides of the subbase. As portions of the concrete slab may lose contact with thebase. Therefore, No external constraints are applied to the concrete slabs whose contact with the baseis maintained by activating the slab self-weight. The dowel bars wereconnected to the slab by the interaction properties and stabilized by their own-weight; no further boundary conditions were applied.

\section{Aircraft loading}

The moving tire is to be modeled as tire imprint area to represent a smooth pavement surface. Traditional pavement analysis usually assumes that the contact stresses at the tire-pavement interface are equal to the tire inflation pressure and are uniformly distributed in a rectangular contact area. The contact area used in this study was calculated according to the Portland Cement Association method [9]. This method simplifies the tire-pavement contact area to a rectangular shape whose dimensions are $0.8712 \mathrm{~L}$ length and $0.6 \mathrm{~L}$ width. The length of the actual contact area $(\mathrm{L})$ is calculated using the following equation:

$$
L=\sqrt{\frac{A_{c}}{0.5227}}
$$




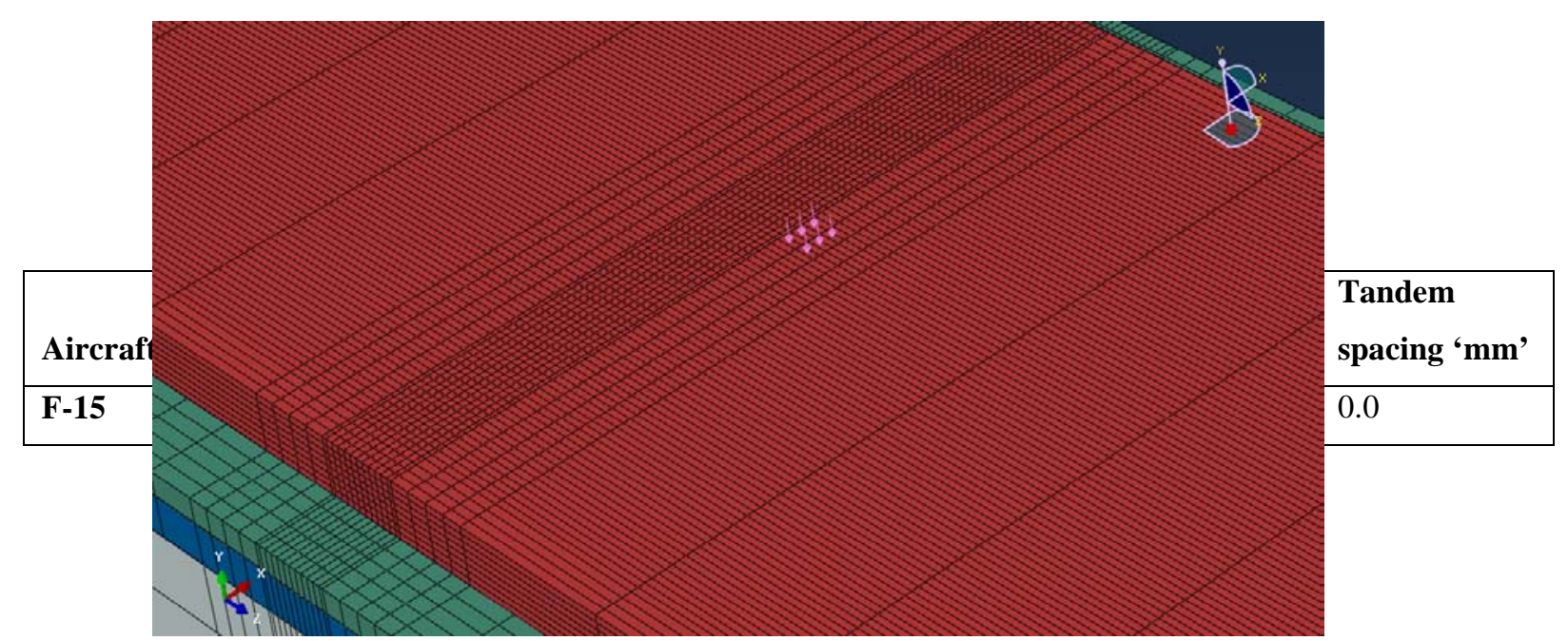

Where Ac is the contact area, which can be obtained by dividing the load on each tire by the tire pressure. The F-15 is used for the parametric cases in this study.The main characteristics of airplane is shown in Table (2) and Figure (3).

Table (2): the main characteristics of airplane

\section{Analysis method}

Figure (3): Single load of F-15

The initial step allows defining boundary conditions, predefined fields, and interactions that are applicable at the very beginning of the analysis. The second step in all cases in this study is set for applying gravity loads and stabilization of the model, the step type is general/ static. The following steps are dedicated for application of the case parameters and conditions. The nonlinear effects are expected, such as large displacements, material nonlinearities, boundary nonlinearities, contact or friction, the NLGEOM command is be used to account for geometric nonlinearities. Once the NLGEOM option is set for a step, setting remains in effect for all subsequent steps[3].

The base used for this case was Item P-306 and the foundation setting was the "very low" case, which allows the responses of pavement to appear more visible and easier to observe and analyze. The slabs are loaded using a single wheel aircraft F-15, with an edge loading at the joint.

\section{Dynamic implicit analysis}

Typical dynamic applications fall into three categories:transient fidelity applications, moderate dissipation applications and quasi-static applications. The analysis product default depends on the presence of contact in the model: analyses involving contact are treated as moderate dissipation applications; analyses without contact are treated as transient fidelity applications. In this study, transient fidelity approach, which based on the concept of moving the load at subsequent positions along the pavement for each new time step, are used. Damping effect is considered in both analysis types.

\section{Damping}

The phenomenon of dissipation of energy in the system through various mechanisms is called damping. ABAQUS provides "Rayleigh" damping for this purpose. It provides a convenient abstraction to damp lower (mass dependent) and higher (stiffness-dependent) frequency range behavior.Rayleigh damping is proportional to the stiffness and mass of the structure.

To define material Rayleigh damping, it has required specifying two Rayleigh damping factors: $\alpha_{R}$ for mass proportional damping and $\beta_{R}$ for stiffness proportional damping. The pavement damping 
is mainly stiffness proportional and hence the first term in the equation is neglected. Here, the Rayleigh coefficient $\beta$ is considered 0.2. Previous studies show that dynamic LTE(s) is not sensitive foundation damping and hence not used in this model[10].

\section{Models Results}

Contour plotsare used to show the value of attributes such as loads or predefined fields variables at a specified step of a model in the certain model database. Output requests in this study mainly focus on showing Mises and maximum principal stresses around deformed dowel hole at the location of maximum stresses at end and beginning of load application for each step of the total analysis history. they also focus on showing stresses and deformation at the critical edge of the loaded and unloaded

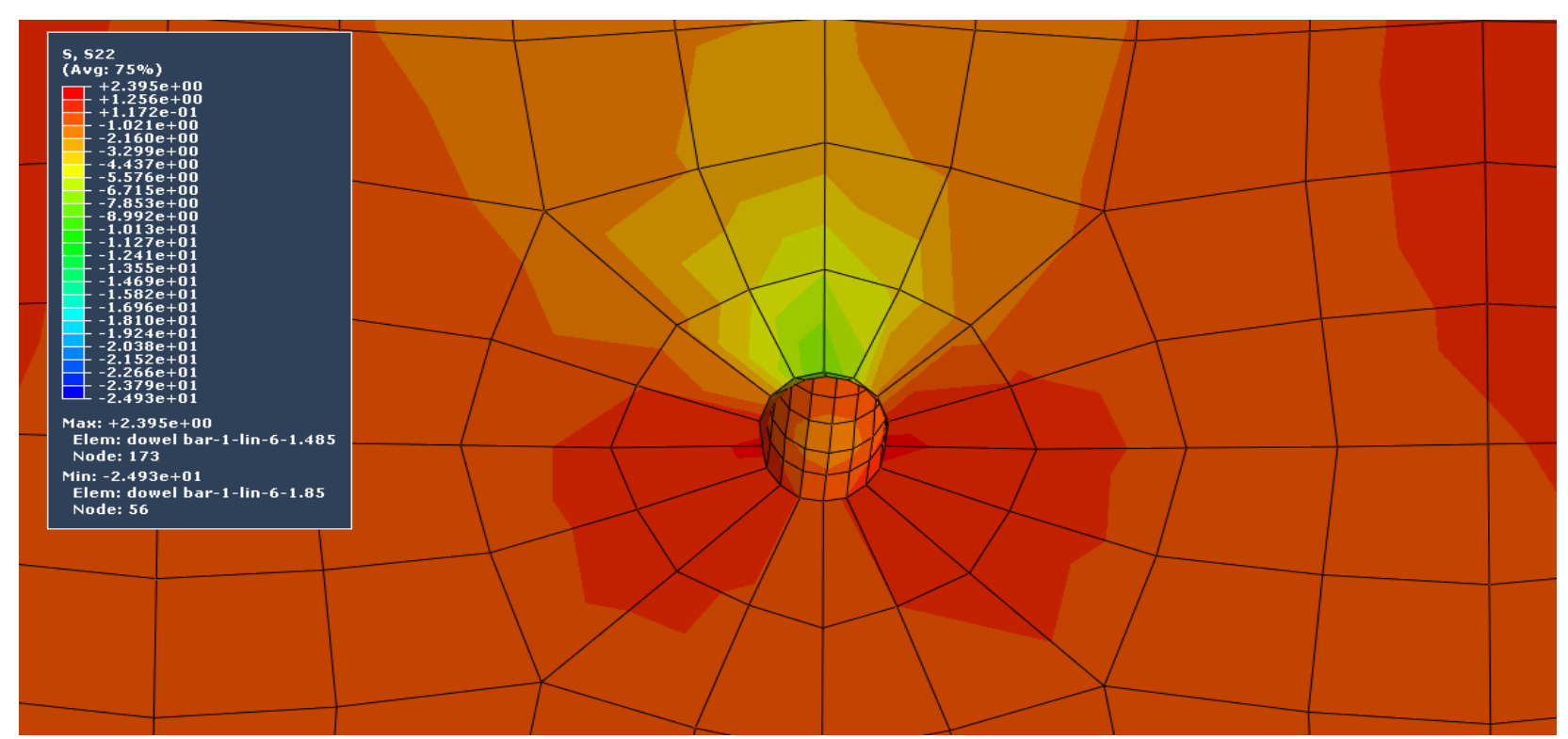

slab. The history of a certain variable would be plotted versus the time of the moving axle (the change in loading position) from a certain point to the joint. The histories developed in four elements, which fall along the inner wheel-path are examined. The location of the four elements selected for every history of a case study of any variable. Two of these elements are located on the slab top and center at loaded slab where the dowel bar located, the other two elements are located on the slab top and center at the unloaded slab a cross of the transverse joint. Figures (4) to (6) shows different general pavementdeformation and stresses results obtained using the developed model. 


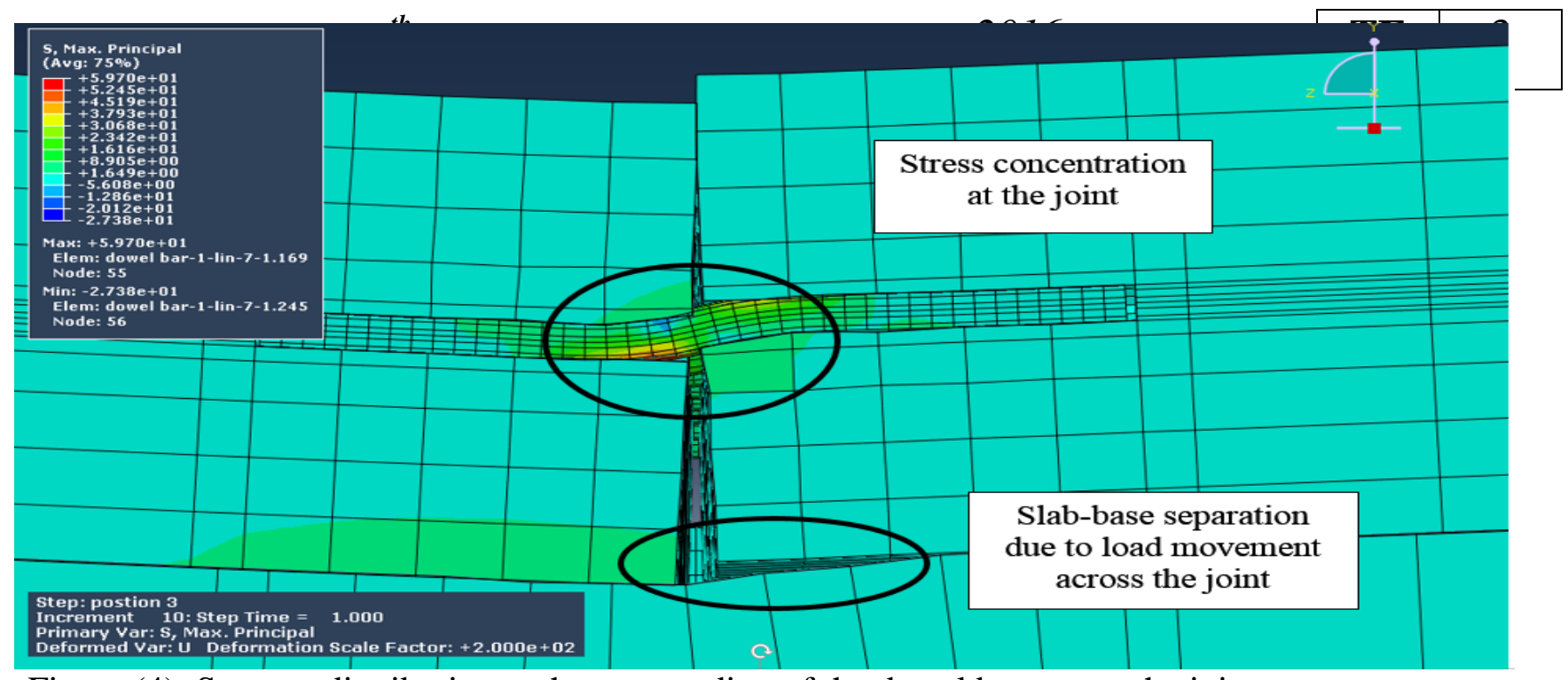

Figure (4): Stresses distribution at the surrounding of the dowel bar across the joint.

Figure (5): Y-Z Plane of the Model Deformation.

Figure (6): Max. Principle stresses at the joint.

\section{Verification of the Model}

Most finite element software can be used as a "black box" by researchers without extensive knowledge of Finite element method. Therefore, FEM packages could be misused resulting in what is termed "garbage in, garbage out" simulations [11]. The most reliable method of investigating the accuracy of the theoretical model is to compare its results with field measurements for the same structure under identical loading conditions. Due to the limited resources and absence of ability to perform a specialized test procedure, the verification process is done first by using approximate solutions, which compare the result from the Conventional analytical solutions. Such comparison set the track for the following verification steps. The next step of verification procedure is to compare obtained load transfer efficiency from NAPTF data with the developed model. Material, boundaries

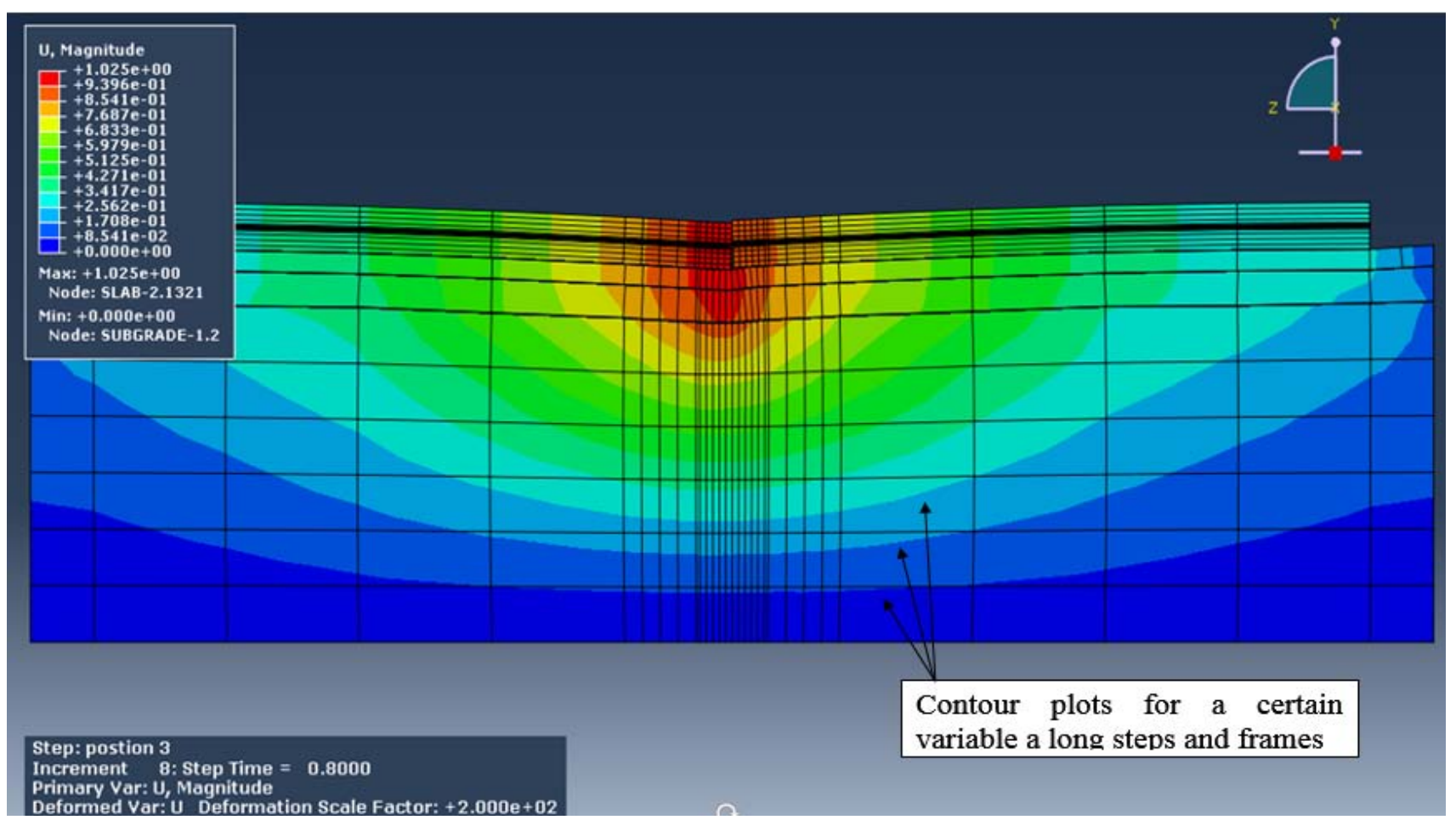

and loads are altered to fit these used in the field test process. Then compare the results from using 
the HWD test on NAPTF sections to verify the validity of the FEM through the comparison of its results to the developed model.

\section{A. Model verification using Westergaard approximations}

A well-accepted analytical solution was chosen to check the accuracy of the approximations made by the developed finite element models. Because of the widespread acceptance of Westergaard's theory, it was chosen for this step. The results obtained from the developed models were compared with the analytical results obtained by Westergaard (1926)[1].

This process involved producing a number of finite element models with varying only in wheel load magnitude, Edge loading is applied for each case. It should be noted that in the analytical method, a circular loading was applied and the boundaries were unlimited. In the FE models, however, the applied loading was rectangular and the boundaries were finite. It was necessary to take into account the load transfer efficiency LTE (S) at the joint. As The Westergaard's solution is valid only for a free edge, while concrete pavements are made of jointed slabs so that when a load is applied at a joint, a portion of this is transferred from the slab loaded to that unloaded[12].

For the evaluation of these reduced stresses, the joint efficiency LTE can be given as:

$$
L T E=\frac{\sigma_{u}}{\sigma_{u}+\sigma_{L}}
$$

Where

$\sigma_{L}=$ maximum tensile stress at the joint edge of the loaded slab

$\sigma_{u}=$ corresponding maximum tensile stress at the joint edge of the unloaded concrete slab.

The reduction factor of the stresses of the slab with a free edge was $\{1-\mathrm{LTE}\}$ and is applied to the Westergaard's solution then compared to corresponding stresses calculated from the ABAQUS FE program. The closed form deflections and stresses were compared against FEM deflections and stresses. The results are given in Table (3).

Values of maximum stresses according to ABAQUS (6.13) and stresses calculated and according to Westergaard's solution for each loading cases are analyzed. It is noted that the differences were ranged between 9- $20 \%$ and the deflection between 13- $25 \%$.This approximation is acceptable for setting the track for the validity of the result as many previous studies stated[12].

Table (3): stresses and deflections from FEM and Westergaard solutions.

\begin{tabular}{|l|l|l|l|l|l|l|}
\hline $\begin{array}{l}\text { Loading case } \\
\text { (MPa) }\end{array}$ & $\begin{array}{l}\text { Westergaard } \\
\text { stress } \\
\text { (MPa) }\end{array}$ & $\begin{array}{l}\text { FEM } \\
\text { stress } \\
\text { (MPa) }\end{array}$ & $\begin{array}{l}\text { Diff. } \\
\mathbf{\%}\end{array}$ & $\begin{array}{l}\text { Westergaard } \\
\text { deflection } \\
\text { (mm) }\end{array}$ & $\begin{array}{l}\text { FEM } \\
\text { deflection } \\
\text { (mm) }\end{array}$ & $\begin{array}{l}\text { Diff. } \\
\text { \% }\end{array}$ \\
\hline $\begin{array}{l}\mathbf{1 . 4 8 2} \\
\mathbf{f}-16 \text { main gear }\end{array}$ & 1.1573 & 1.39653 & $20.67 \%$ & 0.3226 & 0.40323 & $24.99 \%$ \\
\hline $\mathbf{2}$ & 1.5373 & 1.69237 & $10.09 \%$ & 0.43344 & 0.5423 & $25.12 \%$ \\
\hline $\mathbf{3}$ & 2.3062 & 2.53328 & $9.85 \%$ & 0.65016 & 0.739713 & $13.77 \%$ \\
\hline $\mathbf{5}$ & 3.8439 & 4.24068 & $10.32 \%$ & 1.086612 & 1.33536 & $22.89 \%$ \\
\hline
\end{tabular}

\section{B. Model verification using falling weight deflectometer}

Periodic heavy weight deflectometer (HWD) testing was conducted at the NAPTF using KUAB 240 model in April 2004. This verification is limited to calculation of deflection based LTE for MRS test sections using the loaded and unloaded deflections obtained from HWD sensors across the longitudinal joints (dowelled). Implicit dynamic procedure and Damping factor $(\beta)$ is used for simulation the dynamic effect of the load drop. Damping value of 0.2 is used for loads of 35000, 35500, 36000, 36650 and 37500 lbs., respectively to match the FEM predicted deflections with the 
HWD result data documented in (Wadkar,2009)[13].Results of HWD data comparison with the FE model is show inTable (4).

Table (4): Results of HWD data analysis for test item MRS

\begin{tabular}{|c|c|c|c|c|c|c|}
\hline $\begin{array}{l}\text { Loading } \\
\text { case } \\
\text { (Ib.) }\end{array}$ & $\begin{array}{l}\text { FEM } \\
\text { unloaded } \\
(\mathbf{m m} .)\end{array}$ & $\begin{array}{l}\text { FEM } \\
\text { loaded } \\
(\mathrm{mm} .)\end{array}$ & LTE (ס) & $\begin{array}{l}\text { FEM } \\
\text { Unloaded1 } \\
(\mathrm{mm})\end{array}$ & $\begin{array}{l}\text { FEM } \\
\text { Loaded } 1 \\
\text { (mm.) }\end{array}$ & $\begin{array}{l}\text { SD } \\
(\mathbf{m m})\end{array}$ \\
\hline 35000 & 0.390784 & 0.436249 & $89.6 \%$ & 0.225648 & 0.271149 & 0.496797 \\
\hline 35500 & 0.394716 & 0.44096 & $89.51 \%$ & 0.229616 & 0.27586 & 0.505476 \\
\hline 36000 & 0.400612 & 0.448025 & $89.42 \%$ & 0.235512 & 0.281925 & 0.518437 \\
\hline 36500 & 0.404541 & 0.452733 & $89.35 \%$ & 0.239441 & 0.287633 & 0.527074 \\
\hline 37500 & 0.410434 & 0.459792 & $89.26 \%$ & 0.245334 & 0.294692 & 0.540026 \\
\hline \multicolumn{7}{|c|}{ AVERAGE } \\
\hline 36100 & 0.4002174 & 0.4475518 & $89.43 \%$ & 0.2351102 & 0.2822518 & 0.517562 \\
\hline Ranges & & & $92 \%$ & $0.2445 \&$ & $0.2715 \&$ & 0.5755 \\
\hline Accuracy\% & & & 97.2 & 0.29425 & 0.31825 & 89.93 \\
\hline
\end{tabular}

Seismometers of HWD contact the surface of the concrete during testing and measure the deflection from the plate. Therefore, the deflection readings is only for slab deflection due to the HWD not the gravitational force as in the developed FE model. The deflection of the gravity phase is subtract from total deflection before compared to unloaded and loaded deflections results from field HWD test and called (unloaded1) and (loaded 1). The gravitational deflection is found to be $0.11651 \mathrm{~mm}$. then Measure the sum of two deflections (SD) on two sides of joints. According to (wadker.2010) the average LTE (6) for longitudinal joints was computed to be 0.92 respectively. The average SD was 23.02 mils $(0.5755 \mathrm{~mm}$.) for longitudinal joints. The unloaded deflection ranged between 9.78 and 11.77 mils ( 0.2445 and $0.29425 \mathrm{~mm}$.). The loaded deflections ranged between 10.86 and 12.73 mils (0.2715 and 0.31825). Table (4) shows that unloaded and loaded deflection were in the previously mentioned range , which obtained from HWD data analysis. The comparison of calculated deflection LTE from 3D FE analysis with field test results are within the acceptable range. The results show that the FE models results agree qualitatively and quantitatively with the experimentally measured deflections.

\section{Model verification using NAPTF field data}

A comparison was made between the effects of load transfer at the joint in a full-slab finite element model and the full-scale tests data available from testing of CC2 test strip at FAA's NAPTF facility. MRS section was selected. The test sections were loaded using only 4-wheel gear configuration with a constant speed, tire pressure of 210 psi and a nominal load of 55,000 lbs (244.65 kN) per wheel.(NAPTF-Databases). The dual tandem wheel configuration of the NAPTV is simulated in ABAQUS by applying the load on a set of elements covering the loaded footprint area in two-step movement across the joint as shown in Figure (7). The amplitude of tire pressure acting on each of the elements is varied with time to simulate the movement of NAPTV. The max. Principle stress responses in wheel position 1 and position 2 were considered in this analysis and shown in Figure (8). The average LTE (S) of transverse joints under moving wheels was found 0.47 for MRS. The stress based LTE from static 4-wheel loading was compared with that under moving loads already obtained from the strain record analysis in previous studies [13]

Data Validation

LTE (S) for position $1=\frac{2.45415}{(2.45415+2.72957)}=0.4734$ 
LTE (S) for position $2=\frac{2.89655}{(2.89655+3.08708)}=0.4841$

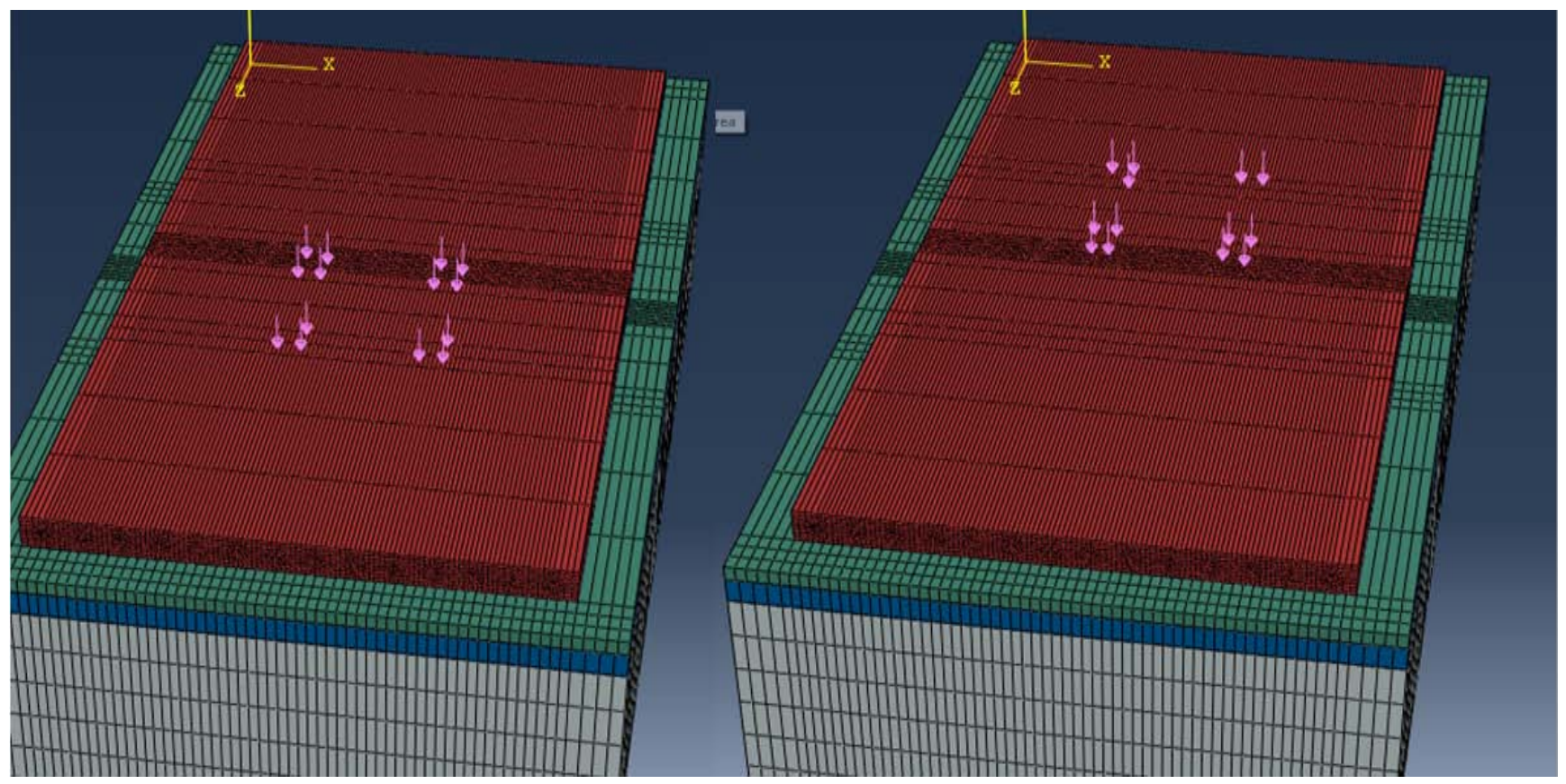

Figure (7): The two-step movement of the load across the joint 


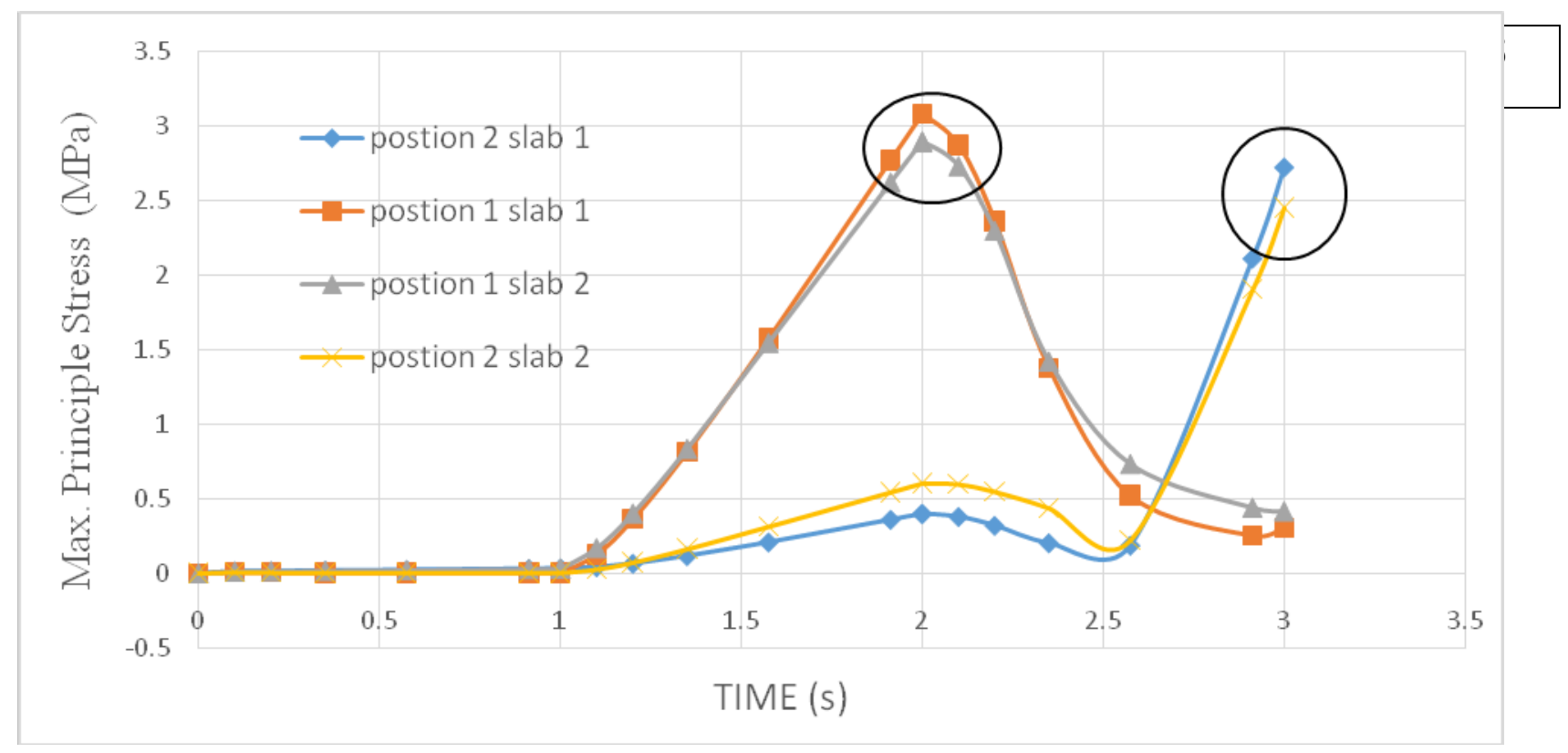

Figure (8): The max. Principle stresses across the joint during load moving from position 1 to positon 2

The computed stress LTEs were found to be similar to the average LTE (S) of transverse joints under moving wheels was found 0.47 for MRS when measured under 4-wheel dynamic gear configuration in an acceptable range. The presented verification procedure illustrates that the developed model is capable of producing almost typically the same results obtained from field studies and therefore increase the confidence in its results. The overall agreement was acceptable, promising and easily to be improved for further studies. Due to flexibility of this model, it can be easily altered in a way that help to investigate other aspects that affect the response of rigid pavements.

\section{CONCLUSIONS}

The following conclusions are made based on the analysis and observations of 3D finite element model representing valuable insight on the behavior of the slab-dowel system when subjected to loading:

1-The change in the bond of dowel bars model result in a significant stress drop across the joint. This observation demonstrates the effectiveness of dowel bars in controlling joint cracks.

2-Using an unbonded interface, whereSeparation condition is allowed, and combined with friction between the slab and base permits a better simulation of the pavement structure, especially under the effect of thermal gradient when gaps initiate between the slab and the supporting layers.

3-Modeling the dowel bars using hexahedron solid brick elements has several advantages especially in locating the areas of high stresses in the concrete surrounding the bars.

4-Using wedge elements for modeling insure uniform meshing around dowel bars to allow the model to capture accurately the dowel responses.

5- Modeling aggregate interlock along the transverse joint using surface-to-surface contact Allow the simulation of a realistic load transfer devices behavior, relative motion, and gap formulation between the slabs along the transverse joint.

6- Results obtained from the developed model show that constraining the lateral sides of the slab, where the tie bars are usually loaded, does not affect the slab response under wheel loads. Therefore 
modeling the tie bars in this case is not essential. However, it is important for modeling the pavement subjected to thermal loading.

7- The distribution of the developed stresses in the pavement along the straight wheel path shows that the stress is constant along the slab length and changes significantly at the joint especially around the dowel holes.

8- Using a moving load allows studying the fatigue cycles the pavement can be subjected to under different wheel configurations. This allow examining the cycles of tension-compression due to wheel loading which may reduce the strength of the concrete and develop more fatigue damage than traditional static analysis.

\section{References}

[1]Analysis of stresses in concrete pavements due to variations of temperature. . Westergaard, H.M. 1926, Highway Research Board, Vols. Vol. 6: 201-215.

[2]M. Ioannides, Michael I. Hammons,. ADVANCED PAVEMENT DESIGN:Finite Element Modeling for Rigid Pavement Joints Report I: Background Investigation: U.S. Department of Transportation Federal Aviation Administration, 1997.

[3] ABAQUS Documentation User's Guide: DassaultSystèmes, Simulia Corp, 2013.

[4] Identification of parameters of concrete damage plasticity constitutive. Jankowiak, T., Lodygowski, T. 2005, Poznan University of Technology, Institute of Structural Engineering (ISE).

[5]NAPTF-Databases. $\quad$ http://www.airporttech.tc.faa.gov/Airport-Pavement/National-AirportPavement-Test-Facility-/NAPTF-Databases .

[6]Edward Guo, LiaRicalde, and IzydorKawa. FAA Finite Element Design Procedure for Rigid Pavements: U.S. Department of Transportation Federal Aviation Administration, 2007.

[7]Characterization of Contact Stresses Between Dowels and Surrounding Concrete in Jointed Concrete Pavement. LI Luoke, TAN Yiqiu, GONG Xiangbing, LI Yunliang. 2009, International Journal of Civil \& Environmental Engineering IJCEE-IJENS Vol: 12 No: 05.

[8]Samir N. Shoukry, Gergis W. Willliam, Mourad Y. Riad, and Sri vaniSirishaMotamarri. Effect of Bonding Force on Stresses in Concrete Slabs: West Virginia University, Department of Civil and Environmental Engineering, Morgantown, 2003.

[9]Huang, Yang H. Pavement Analysis and Design,second edition: Prentice Hall, 2003.

[10]Xinhua YU, Yumin ZHOU Edward Guo. Considering, Joint Load Transfer Efficiency of Rigid Pavement Dynamic Effects under a Single Moving Load. 2010.

[11]Liu, G. R. The Finite Element Method A Practical Course. Second Edition. 2014.

[12]Stress-Prediction Model for Airport Pavements with Jointed Concrete Slabs. Parisi, CiroCaliendo and Alessandra. 2010, JOURNAL OF TRANSPORTATION ENGINEERING (C) ASCE. 
Proceedings of the $\mathbf{1 1}^{\text {th }}$ ICCAE-11 Conference, 19-21 April, 2016

[13] Wadkar, Ashish. Study of Load Transfer Efficiency of Airfield Rigid Pavement Joints Based On Stresses andDeflections. 2009. 